EXTENDED REPORT

\title{
Comparison of long term outcome of patients with rheumatoid arthritis presenting with undifferentiated arthritis or with rheumatoid arthritis: an observational cohort study
}

\author{
J van Aken*, H van Dongen*, S le Cessie, C F Allaart, F C Breedveld, T W J Huizinga
}

Ann Rheum Dis 2006;65:20-25. doi: 10.1136/ard.2005.038471

See end of article for authors' affiliations

Correspondence to:

Professor T W J Huizinga,

Department of

Rheumatology, Leiden University Medical Centre, PO Box 9600, 2300 RC, Leiden, The Netherlands; T.W.J.Huizinga@lumc.nl

Accepted 15 May 2005 Published Online First 18 May 2005

\begin{abstract}
Background: The outcome of undifferentiated arthritis (UA) ranges from remission to rheumatoid arthritis (RA) fulfilling the American College of Rheumatology (ACR) classification criteria.

Objectives: To report the outcome of UA after 1 year of follow up and compare the disease course of patients who presented with UA, but evolved into RA within 1 year (UA-RA group), with that of patients who presented with RA fulfilling the ACR criteria (RA-RA group).

Methods: The diagnosis of 330 patients who presented with UA was recorded at 1 year. The UA-RA and RA-RA groups were then followed up for 3 more years. Outcome measurements were radiographic progression, disease activity, and functional capacity.

Results: From 330 patients who were diagnosed UA, 91 had evolved into RA at 1 year; 62 patients had presented with RA. No significant differences were detected between the UA-RA and RA-RA groups in median Sharp/van der Heijde score at baseline, radiographic progression rates, disease activity, and functional capacity. However, significantly more disease modifying antirheumatic drugs were prescribed in the RA-RA group.

Conclusion: The disease outcome of patients who present with UA that evolves into RA within 1 year is the same as that of patients who present with RA as measured by radiographic progression, disease activity, and functional capacity.
\end{abstract}

l various studies of patients with recent onset arthritis, 6$55 \%$ of the patients who presented with undifferentiated arthritis (UA) progressed into rheumatoid arthritis (RA) according to the American College of Rheumatology (ACR) classification criteria or according to the rheumatologist. Multivariate analysis of characteristics of these patients showed that the presence of antibodies to cyclic citrullinated peptide (anti-CCP), polyarthritis, symmetric arthritis, and erosions on radiographs predict the development of RA. Among these characteristics, anti-CCP has the highest specificity and positive predictive value for RA. ${ }^{2}$ Thus, either by clinical or by serological data, clinicians will be confronted with patients with UA who are likely to develop RA. The natural course of patients who present with UA and subsequently develop RA is unknown compared with patients who present with RA. In patients with RA many studies have demonstrated the benefit of the early initiation of disease modifying antirheumatic drugs (DMARDs), resulting in less disease activity and reduction of radiographic joint damage. ${ }^{3-5}$ Patients included in these studies fulfilled the 1987 ACR classification criteria for RA. ${ }^{6}$ However, the ACR classification criteria were not developed for the purpose of early diagnosis as is illustrated by the fact that a minority of patients with inflammatory polyarthritis fulfilled the ACR criteria at the first visit. ${ }^{7}$

Although patients with RA benefit from early aggressive treatment, ${ }^{8}$ it is unknown whether patients with UA whose disease will evolve into RA will also benefit from such a treatment strategy. Hypothetically, if at presentation the duration of complaints is similar, patients who present with UA might have a disease course that evolves more slowly than that of patients who present with RA (fig l). In the worst situation, the "window of opportunity" for early treatment to induce long term disease modification in the patients who presented with UA has been passed once the diagnosis RA is made, and long term outcome will be comparable or worse than patients who were diagnosed with RA at presentation and treated immediately.

Here, we describe the 1 year diagnosis and outcome of patients who presented with UA, and compare the disease course of the patients with UA who had developed RA within l year after presentation (UA-RA group) with that of patients who presented with RA (RA-RA group). Radiographic progression was the major outcome measure; disease activity and functional capacity were minor outcome measures.

\section{PATIENTS AND METHODS \\ Patients}

The Leiden Early Arthritis Clinic (EAC) was started in 1993. General practitioners were asked to refer patients with suspected arthritis as soon as possible. Patients were included in the EAC cohort if a rheumatologist confirmed the suspected arthritis and the symptoms of arthritis did not exceed 2 years; for details of this cohort see Van der HorstBruinsma et al. ${ }^{9}$ Patient history, general physical examination, a painful and swollen joint count, laboratory tests, questionnaires, and radiographic joint scores were performed at inclusion and at the follow up visits. Based on the test

Abbreviations: $A C R$, American College of Rheumatology; $C C P$, cyclic citrullinated peptide; CRP, C reactive protein; DAS, Disease Activity Score; DMARD, disease modifying antirheumatic drug; EAC, Early Arthritis Clinic; ESR, erythrocyte sedimentation rate; $H A Q$, Health Assessment Questionnaire; RA, rheumatoid arthritis; RF, rheumatoid factor; UA, undifferentiated arthritis 


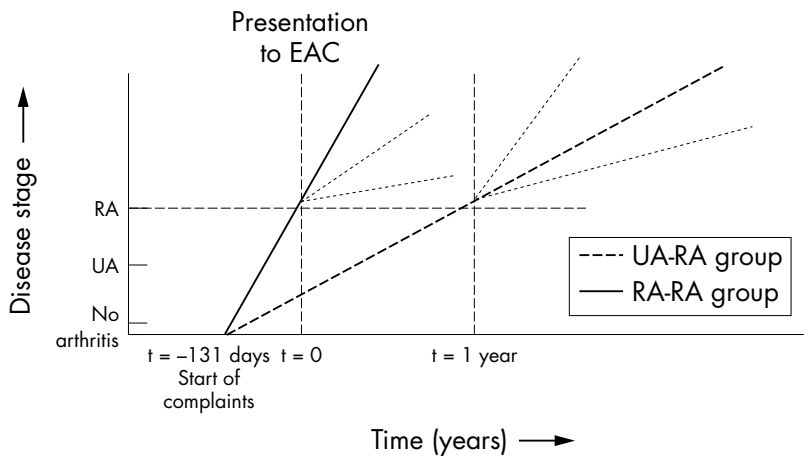

Figure 1 Hypothetical disease course of UA and RA.

results, a diagnosis was recorded at the second visit, 2 weeks later, but could be revised during follow up.

\section{Study design}

From the EAC database (fig 2), patients diagnosed with UA at the second visit were selected and their subsequent diagnosis was recorded at 1 year. UA comprised arthritis of unknown cause and "probable RA" according to the 1958 ACR criteria. ${ }^{10}$ The group of patients diagnosed with UA who evolved into RA fulfilling the 1987 ACR criteria within 1 year (UA-RA group) was followed up for 4 years. Because these patients had the opportunity to be treated with DMARDs as soon as the diagnosis was made, the long term outcome was compared with that of a group of patients in whom RA was diagnosed at the first and/or second visit and who still had RA after 1 year, and who were treated with DMARDs as soon as RA was diagnosed (RA-RA group).

\section{Outcome measurements}

Major outcome measurements were radiographic joint damage and calculated radiographic progression rate.

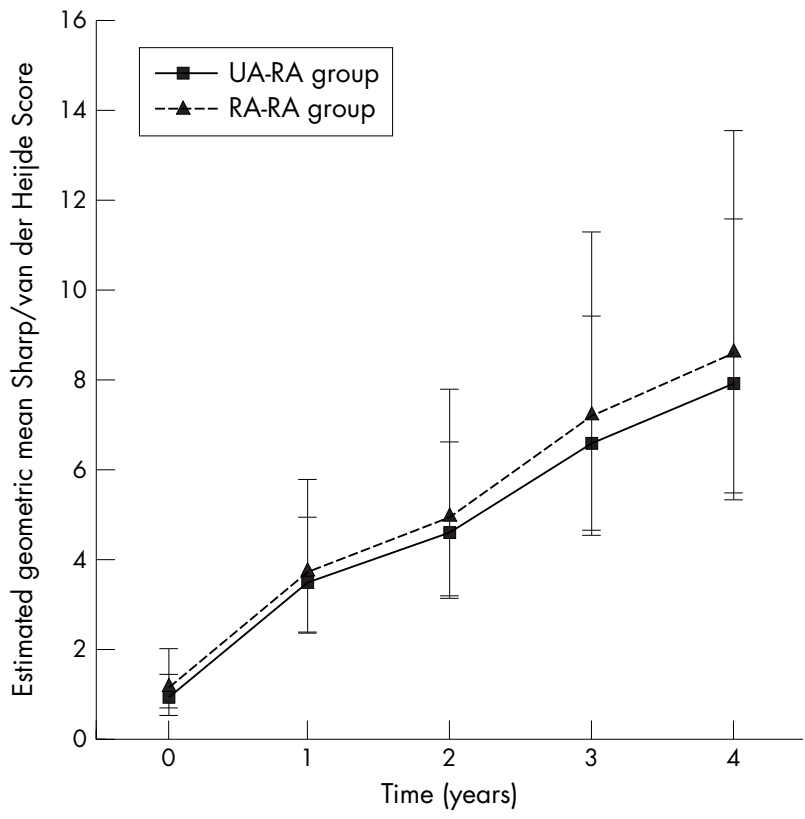

Figure 3 Estimated geometric mean Sharp/van der Heijde Score $195 \%$ confidence interval) of the UA-RA and RA-RA groups from baseline to 4 years.

Radiographs of hands and feet were taken at inclusion in the EAC and yearly thereafter. Radiographic scoring according to the Sharp/van der Heijde method ${ }^{11}$ was performed in random order by an experienced rheumatologist who was unaware of the clinical data and the study questions. The intraclass correlation coefficient for the assessor's scoring was 0.95 , as measured in 62 patients.

Minor outcome measurements were disease activity, functional capacity, erythrocyte sedimentation rate (ESR) in

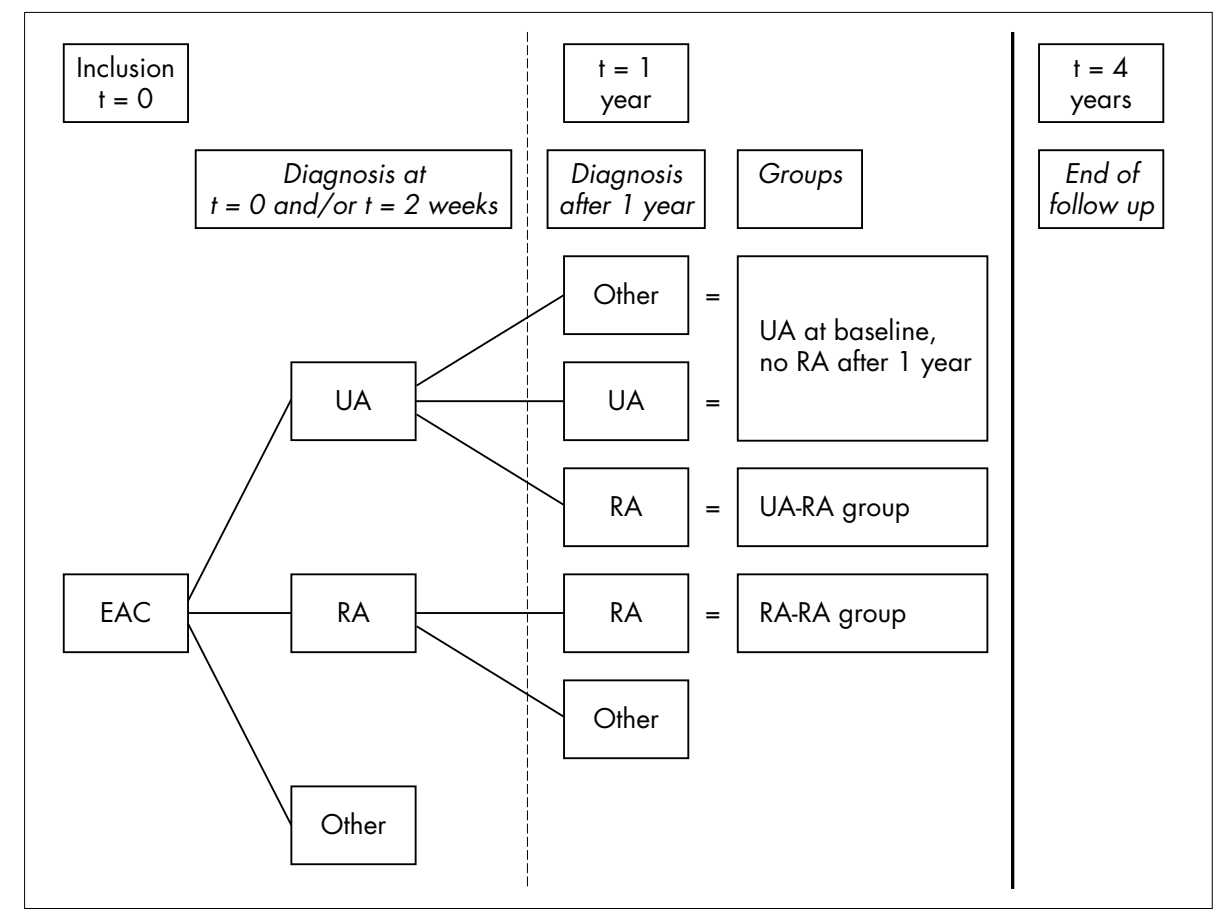

Figure 2 Flow diagram for definition of the groups. 
Table 1 Diagnosis after 1 year of follow up of patients who presented with UA and the numbers of patients who had ended EAC follow up at 1 year, and their main reason for doing so

\begin{tabular}{|c|c|c|c|}
\hline Diagnosis at 1 year & $\begin{array}{l}\text { Patients } \\
\text { No }(\%)\end{array}$ & $\begin{array}{l}\text { Patients who } \\
\text { ended follow up } \\
\text { (n) }\end{array}$ & $\begin{array}{l}\text { Main reason for end of follow up } \\
\text { No (\%) }\end{array}$ \\
\hline Arthritis of unknown cause & $134(40.6)$ & 76 & Remission 57 (75) \\
\hline Rheumatoid arthritis & $91(27.6)$ & 9 & $\begin{array}{l}\text { Death } 3 \text { (33) } \\
\text { Remission } 3 \text { (33) } \\
\text { Refusal } 1 \text { (11) } \\
\text { Other/unknown } 2 \text { (22) }\end{array}$ \\
\hline Probable RA & $39(11.8)$ & 9 & Remission 7 (78) \\
\hline Osteoarthrosis/arthritis & 11 (3.3) & 10 & End of treatment $7(70)$ \\
\hline Psoriatic arthritis & $8(2.4)$ & 2 & Remission 2 (100) \\
\hline Reactive arthritis & $6(1.8)$ & 6 & Remission 6 (100) \\
\hline Crystal induced arthritis & $4(1.2)$ & 3 & EAC protocol $3(100)$ \\
\hline Lyme arthritis & $4(1.2)$ & 2 & Remission 2 (100) \\
\hline Paraneoplastic arthritis & $3(0.9)$ & 2 & $\begin{array}{l}\text { Remission } 1(50) \\
\text { Life threatening illness } 1 \text { (50) }\end{array}$ \\
\hline Systemic lupus erythematosus & $2(0.6)$ & 0 & \\
\hline Palindromic RA & $1(0.3)$ & 1 & Moved house 1 (100) \\
\hline Spondyloarthropathy & $1(0.3)$ & 1 & EAC protocol 1 (100) \\
\hline Unknown cause & $6(1.8)$ & 6 & Remission 4 (67) \\
\hline Other causes & $20(6.1)$ & 10 & Remission 4 (40) \\
\hline
\end{tabular}

the lst hour, and C reactive protein (CRP) concentration. Disease activity was calculated by a modified version of the disease activity score (DAS) $)^{8}$ :

$(0.54 \times(\sqrt{ }$ Ritchie score $)+0.065 \times($ swollen joint score $)+$

$0.33 \times \ln \mathrm{ESR}+0.224)$.

Functional capacity was measured by the Health Assessment Questionnaire (HAQ). ${ }^{12}$

\section{Statistical analysis}

Differences between patient characteristics were tested with the Mann-Whitney $U$ test or the $\chi^{2}$ test. For each patient separately, simple linear regression was used to fit the course of the radiographic progression in time. Progression rates were calculated for varying time intervals, assuming that radiographic damage progresses at a constant rate. ${ }^{13}$ The slopes of these regression lines estimate the average increase in Sharp/van der Heijde score per year. Differences between slopes of the groups of interest were tested with the MannWhitney U test.

To construct the radiographic progression as depicted in fig 3, the geometric mean of the Sharp/van der Heijde scores was estimated using a linear mixed model, in which account was taken of missing measurements. ${ }^{15}$ Differences in disease activity and functional capacity were compared with a linear mixed model. All tests were two tailed and p values $\leqslant 0.05$ were considered significant.

\section{RESULTS}

\section{Outcome of UA after 1 year}

Between 1993 and 1999, 1064 patients were included in the EAC. At presentation, 330 patients were diagnosed with UA. Table 1 shows the diagnosis after 1 year of follow up of patients who had presented with UA and the numbers of patients who had ended follow up and their reasons for doing so. Ninety one patients had developed RA according to the 1987 ACR criteria (UA-RA group).

\section{Patient characteristics at baseline}

Table 2 shows the baseline characteristics of the UA-RA group, the RA-RA group, and the group of patients with UA who did not develop RA within 1 year. The UA-RA group differed from the RA-RA group in duration of morning

\begin{tabular}{|c|c|c|c|c|}
\hline Patient characteristics & $\begin{array}{l}\text { RA-RA group } \\
(n=62)\end{array}$ & p Value* & $\begin{array}{l}\text { UA-RA group } \\
(n=91)\end{array}$ & $\begin{array}{l}\text { UA at presentation, } \\
\text { no } R A \text { at } 1 \text { year } \\
\text { ( } n=238)\end{array}$ \\
\hline Age (years) & $53(42-72)$ & 0.683 & $55(44-65)$ & $46(35-58)$ \\
\hline Female patients & $43(69)$ & 0.492 & $58(64)$ & $119(50)$ \\
\hline Duration of symptoms at first visit (days) & $130(61-278)$ & 0.611 & $131(73-230)$ & $81(20-164)$ \\
\hline Duration of morning stiffness (min) & $90(45-150)$ & 0.035 & $60(18-120)$ & $15(0-60)$ \\
\hline Number of swollen joints & $7(5-8)$ & $<0.001$ & $4(2-6)$ & $2(1-3)$ \\
\hline Modified DAS score & $3.5(3.1-4.0)$ & 0.012 & $3.2(2.7-3.7)$ & $2.3(1.9-2.8)$ \\
\hline Rheumatoid factor positive & $44(71)$ & 0.001 & $38(42)$ & $28(12)$ \\
\hline Anti-CCP antibodies & $35 / 59(59)$ & 0.397 & $43 / 83(52)$ & $16(8.2)$ \\
\hline $\operatorname{ESR}(\mathrm{mm} / 1 \mathrm{st} h)$ & $38(20-56)$ & 0.695 & $31(19-53)$ & $18(9-37)$ \\
\hline CRP (mg/l) & $24(9-41)$ & 0.414 & $17(8-46)$ & $10(4-26)$ \\
\hline$H A Q$ score & $1.0(0.6-1.4)$ & 0.184 & $0.8(0.4-1.2)$ & $0.6(0.1-1.0)$ \\
\hline $\begin{array}{l}\text { Erosive disease at baseline (hands and feet } \\
\text { radiographs) }\end{array}$ & $18 / 60(30)$ & 1.000 & $26 / 88(30)$ & $20(13)$ \\
\hline Sharp/van der Heijde score & $1(0-4)$ & 0.281 & $0(0-3)$ & $0(0-0)$ \\
\hline
\end{tabular}




\begin{tabular}{|c|c|c|c|c|}
\hline & \multicolumn{2}{|c|}{$\begin{array}{l}\text { UA-RA group } \\
(n=91)\end{array}$} & \multicolumn{2}{|c|}{$\begin{array}{l}\text { RA-RA group } \\
(n=62)\end{array}$} \\
\hline & $\mathbf{n}$ & $\begin{array}{l}\text { Median } \\
\text { (IQR) }\end{array}$ & $\mathbf{n}$ & $\begin{array}{l}\text { Median } \\
\text { (IQR) }\end{array}$ \\
\hline \multicolumn{5}{|c|}{ Sharp/van der Heijde score } \\
\hline Baseline & 88 & $0(0-3)$ & 60 & $1(0-4)$ \\
\hline 1 Year & 79 & $4(0-13)$ & 56 & $5(0-18)$ \\
\hline 2 Years & 71 & $8(0-17)$ & 48 & $5(1-27)$ \\
\hline 3 Years & 66 & $10(2-20)$ & 45 & $11(2-26)$ \\
\hline 4 Years & 53 & $9(2-30)$ & 41 & $15(4-27)$ \\
\hline \multicolumn{5}{|c|}{ Radiographic progression rate } \\
\hline Slope $0-1$ year* & & $2(0-8)$ & & $2(0-10)$ \\
\hline Slope $0-2$ years* & & $3(0-8)$ & & $1(0-8)$ \\
\hline Slope $0-4$ years* & & $2(0-7)$ & & $2(0-4)$ \\
\hline Slope $1-4$ years* & & $2(0-8)$ & & $1(-1-3)$ \\
\hline Slope $2-4$ years* & & $2(-1-8)$ & & $2(0-5)$ \\
\hline
\end{tabular}

stiffness, number of swollen joints, modified DAS, and percentage of patients who were rheumatoid factor (RF) positive. These differences reflect the ACR criteria for RA.

The patients with UA who did not develop RA within 1 year were significantly different at baseline from both the UA-RA group and the RA-RA group in all characteristics.

\section{Radiographic joint damage}

No significant differences were detected between the UA-RA and RA-RA groups for median Sharp/van der Heijde score (table 3, fig 3). At 4 years $75 \%$ of all patients in both the UARA group (77\%) and the RA-RA group (73\%) had erosive disease compared with $30 \%$ at baseline.
Table 4 Number (\%) of patients receiving prescribed DMARDs at 3 months, 1, 2, 3, and 4 years in the UA-RA and RA-RA groups

\begin{tabular}{llll}
\hline Time points & $\begin{array}{l}\text { UA-RA group } \\
(\mathbf{n}=91)\end{array}$ & $\begin{array}{l}\text { RA-RA group } \\
(\mathbf{n}=62)\end{array}$ & p Value \\
\hline 3 Months & $42(46)$ & $62(100)$ & $<0.001$ \\
1 Year & $62(68)$ & $58(94)$ & $<0.001$ \\
2 Years & $63(69)$ & $56(90)$ & $<0.001$ \\
3 Years & $60(66)$ & $49(79)$ & 0.04 \\
4 Years & $52(57)$ & $48(77)$ & 0.003 \\
\hline
\end{tabular}

\section{Disease activity and functional capacity}

Figures 4A-D show the mean DAS, HAQ, ESR, and CRP of the two groups. During follow up no significant differences were seen.

\section{DMARDs}

Table 4 shows the use of DMARDs. At all time points significantly fewer DMARDs were prescribed in the UA-RA group than in the RA-RA group. Frequently prescribed DMARDs were hydroxychloroquine, sulphasalazine, and methotrexate or a combination of these. Prednisolone was also prescribed as single drug or combination therapy. Gold, azathioprine, and ciclosporin were prescribed in a minority of patients, and biological agents were not prescribed at all.

In the UA-RA group, 16/91 patients never received DMARDs during the follow up period of 4 years. Of these 16 patients, 11 were RF negative and in 10 patients erosive disease was seen during follow up.

\section{Dropouts}

Follow up of 3-4 years was available for 124 patients. Twenty nine patients were lost to follow up (dropouts). In the UA-RA group five patients were in remission, two refused follow up,
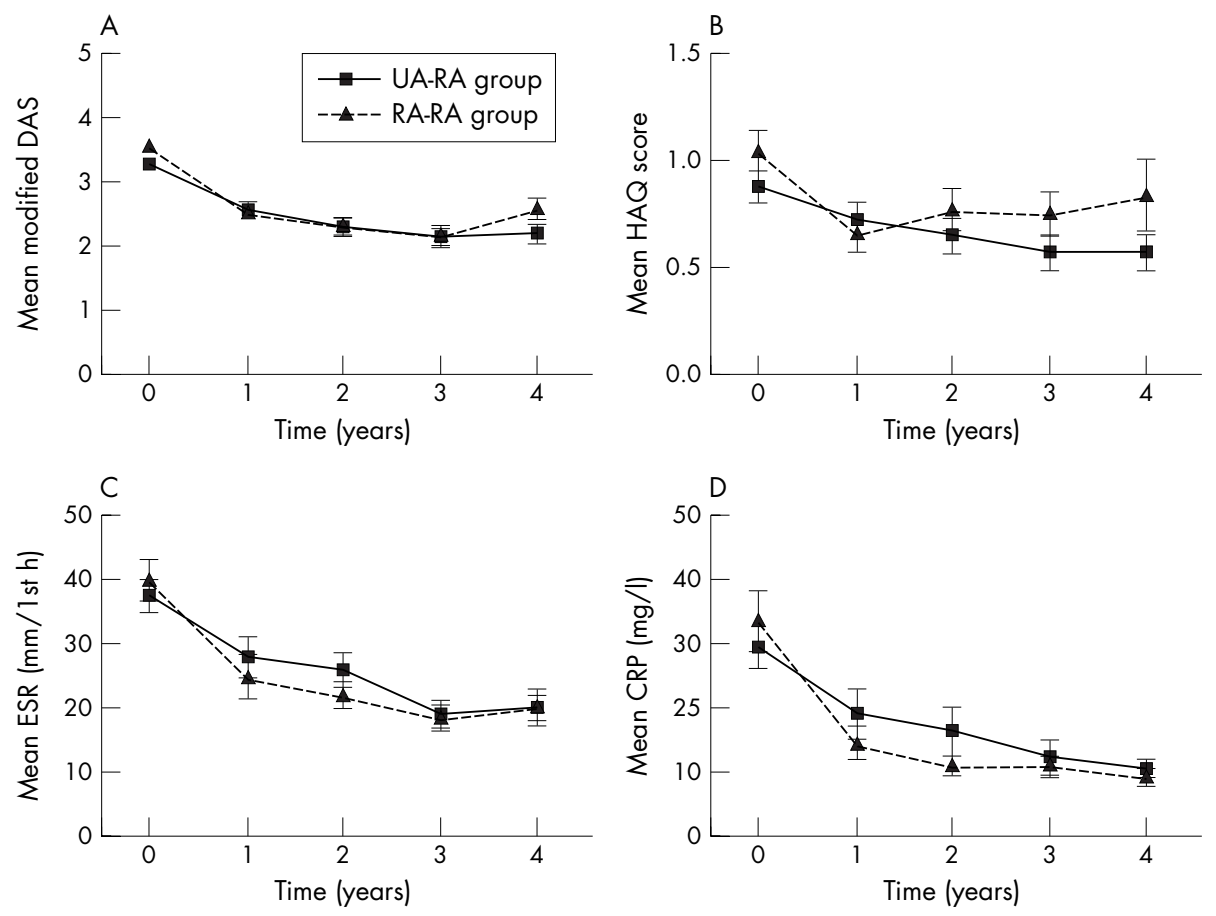

Figure 4 Secondary outcome values of the UA-RA and RA-RA groups from baseline to 4 years. (A) Modified Disease Activity score; (B) Health Assessment Questionnaire score; (C) erythrocyte sedimentation rate in $\mathrm{mm} / 1 \mathrm{st} h$; (D) C reactive protein concentration. Mean values (SEM). 
Table 5 Baseline characteristics of dropouts (before or at 3 years of follow up) versus completers

\begin{tabular}{|c|c|c|c|c|c|c|}
\hline \multirow[b]{2}{*}{ Patient characteristics } & \multicolumn{3}{|l|}{ UA-RA group } & \multicolumn{3}{|l|}{ RA-RA group } \\
\hline & $\begin{array}{l}\text { Dropouts } \\
\text { ( } \mathrm{n}=19)\end{array}$ & $\begin{array}{l}\text { Completers } \\
(\mathrm{n}=72)\end{array}$ & p Value & $\begin{array}{l}\text { Dropouts } \\
(\mathrm{n}=10)\end{array}$ & $\begin{array}{l}\text { Completers } \\
(n=52)\end{array}$ & p Value \\
\hline Age (years) & $64(46-75)$ & $55(44-63)$ & 0.099 & $57(36-85)$ & $53(46-69)$ & 0.745 \\
\hline Female patients & 57 & 65 & 0.598 & 60 & 71 & 0.479 \\
\hline Duration of symptoms at first visit (days) & $102(61-209)$ & $144(78-250)$ & 0.381 & $159(63-275)$ & $126(59-290)$ & 0.851 \\
\hline Duration of morning stiffness (min) & $60(30-180)$ & $60(15-120)$ & 0.341 & $75(41-135)$ & $90(45-180)$ & 0.875 \\
\hline Number of swollen joints & $5(3-8)$ & $4(2-5)$ & 0.087 & $7(4-8)$ & $7(5-8)$ & 0.658 \\
\hline Modified DAS score & $3.3(2.8-4.2)$ & $3.1(2.6-3.6)$ & 0.218 & $3.5(2.9-4.7)$ & $3.5(3.1-4.0)$ & 0.626 \\
\hline RF positive & 26 & 47 & 0.127 & 60 & 73 & 0.457 \\
\hline Anti-CCP antibodies & 42 & 55 & 0.435 & 50 & 61 & 0.725 \\
\hline $\operatorname{ESR}(\mathrm{mm} / 1 \mathrm{st} \mathrm{h})$ & $37(25-65)$ & $30(18-50)$ & 0.091 & $46(25-61)$ & $35(19-57)$ & 0.410 \\
\hline $\mathrm{CRP}(\mathrm{mg} / \mathrm{l})$ & $57(13-74)$ & $11(7-32)$ & 0.002 & $19(9-44)$ & $27(9-42)$ & 0.984 \\
\hline $\mathrm{HAQ}$ score & $1.0(0.12-1.37)$ & $0.75(0.5-1.12)$ & 0.852 & $1.31(0.65-1.75)$ & $1.0(0.5-1.37)$ & 0.382 \\
\hline Erosive disease (hands and feet radiographs) & 33 & 29 & 0.695 & 44 & 28 & 0.309 \\
\hline
\end{tabular}

five had died, one discontinued because of a concomitant illness, and in six patients the cause was unclear. In the RARA group four patients were in remission, two refused follow up, one had died, one discontinued because of a concomitant illness, and in two patients the cause remained unclear. Table 5 compares the baseline characteristics of the dropouts with those of patients with 4 year follow up (completers). Only CRP in the UA-RA group was significantly higher in the dropout group than for the completers

\section{DISCUSSION}

Here, the hypothesis was tested whether patients with UA who developed RA within 1 year have a different disease course than those who presented to the Leiden EAC with RA fulfilling the ACR criteria. ${ }^{6}$ Of the 330 patients who initially presented with UA, 91 (28\%) had developed RA within 1 year. Although the patients with UA might hypothetically have evolved more slowly towards RA, joint damage, disease activity, and functional capacity were the same in both groups over a follow up period of 4 years.

$\mathrm{UA}$ is a commonly encountered problem in daily practice. In one third of patients with recent onset arthritis it is not possible to come to a definite diagnosis at presentation. Overall, $63 \%$ of the patients at the Leiden EAC had a self limiting disease course and $28 \%$ progressed from UA to RA. Other studies show that $6-55 \%$ of patients with UA will eventually evolve into RA. ${ }^{1}$ These percentages are dependent on the different inclusion criteria, recruitment procedures, and disease criteria. For example, low percentages are found in RF negative patients with monarthritis, ${ }^{16}$ and higher percentages are found in inception cohorts where patients with polyarthritis are diagnosed with RA, regardless of fulfilment of the ACR criteria. ${ }^{17}$

Despite the fact that many studies have tried to describe the natural history of UA, the long term outcome of the subgroup of patients with UA who develop RA has never been described. As can be expected, the UA-RA and RA-RA groups differed at presentation in duration of morning stiffness, number of swollen joints, modified DAS, and percentage of RF positive patients, because these variables are directly or indirectly part of the 1987 ACR classification criteria for RA. The presence of anti-CCP was equal in both groups and is similar to previous studies. ${ }^{18}$ The group of patients with UA who did not develop RA within 1 year differed significantly in all patient characteristics at baseline from the other two groups. This is a very heterogeneous group considering the diagnosis after 1 year, but all these patients were diagnosed with UA at baseline.

Median symptom duration is about the same in both groups. However, given the large variation in symptom duration some misclassification of patients might have occurred. Theoretically, patients with UA who presented with short symptom duration might have belonged to the RA-RA group, and patients with RA with very long symptom duration might have had the chance of being included in the UA-RA group. However, analysis of subgroups with different intervals of symptom duration did not show an effect on joint damage.

In the dropout analysis, only CRP in the UA-RA group was significantly higher in the dropout group than for the completers. These data argue against the possibility that the UA-RA group equals the RA-RA group because the dropouts in the UA-RA group were the patients who presented with a milder disease, and only the patients with more aggressive disease completed the follow up.

At all time points, the UA-RA group received fewer DMARDs than the RA-RA group. In this observational study, this might reflect a historical development in DMARD prescription. It also might be a confounding by indication, as clinicians are inclined to prescribe DMARDs to patients who they expect to have a more destructive disease course. Then, patients in the RA-RA group might have a more aggressive disease course that is modified by DMARDs. However, the power to detect an effect of the presence or absence of DMARD use on radiographic progression was too low given the small number of patients with RA who did not use DMARDs $(n=16)$. In the UA-RA group, 16/91 patients did not receive DMARDs during the 4 year follow up. Although 11 of these patients were RF negative, 10 had erosive disease. However, with a median radiographic progression of one point a year, this subgroup had less progressive disease than the group treated with DMARDs. A randomised clinical trial with DMARDs in patients with UA would be the most appropriate study design to overcome this issue.

The overall outcome of UA poses challenging treatment goals. Patients with UA who will go into remission will need treatment aimed at reducing symptoms, whereas patients prone to progress to RA will need treatment to improve their long term outcome as well. Furthermore, there is a need for new criteria to identify patients with UA that will evolve into RA, as the current ACR criteria for RA are not suitable for this purpose. This study implies that the long term outcome of patients who present with UA which evolves into RA is the same as that of patients who present with RA. New serological tests combined with clinical judgment will help to determine which patients with UA are most likely to develop RA. Randomised clinical trials in such patients with UA are currently under way to test whether this group of patients may benefit from very early DMARD treatment. 


\section{ACKNOWLEDGEMENTS}

This work was supported by the Dutch Arthritis Foundation (NR-0201-301) and by the Netherlands Organisation for Scientific Research (NWO, grant No 920-03-259).

\section{Authors' affiliations}

J van Aken, H van Dongen, C F Allaart, F C Breedveld, T W J Huizinga,

Department of Rheumatology, Leiden University Medical Centre, Leiden, The Netherlands

S le Cessie, Department of Medical Statistics, Leiden University Medical Centre, Leiden, The Netherlands

Competing interest: none declared

*Drs J van Aken and $\mathrm{H}$ van Dongen contributed equally to this work

Ethics approval and patient consent: The "Commissie Medische Ethiek" of the Leiden University Medical Centre approved the protocol of the Leiden Early Arthritis Clinic (EAC). All the patients who were included in the Leiden EAC signed an informed consent.

\section{REFERENCES}

1 Verpoort KN, van Dongen $\mathrm{H}$, Allaart CF, Toes RE, Breedveld FC Huizinga TW. Undifferentiated arthritis-disease course assessed in several inception cohorts. Clin Exp Rheumatol 2004;22(suppl 35):S7.

2 Schellekens GA, Visser H, de Jong BA, van den Hoogen FH, Hazes JM, Breedveld FC, et al. The diagnostic properties of rheumatoid arthritis antibodies recognizing a cyclic citrullinated peptide. Arthritis Rheum 2000:43:155-63.

3 Hannonen P, Mottonen T, Hakola M, Oka M. Sulfasalazine in early rheumatoid arthritis. A 48-week double-blind, prospective, placebo-controlled study. Arthritis Rheum 1993;36:1501-9.

4 Lard LR, Visser H, Speyer I, vander Horst-Bruinsma IE, Zwinderman AH, Breedveld FC, et al. Early versus delayed treatment in patients with recentonset rheumatoid arthritis: comparison of two cohorts who received different treatment strategies. Am J Med 2001;111:446-51.
5 Van der Heide A, Jacobs JW, Biilsma JW, Heurkens AH, Booma-Frankfort C, van der Veen $M J$, et al. The effectiveness of early treatment with antirheumatic drugs. A randomized, controlled trial. Ann Intern Med 1996;124:699-707.

6 Arnett FC, Edworthy SM, Bloch DA, McShane DJ, Fries JF, Cooper NS, et al. The American Rheumatism Association 1987 revised criteria for the classification of rheumatoid arthritis. Arthritis Rheum 1988;31:315-24.

7 Huizinga TW, Machold KP, Breedveld FC, Lipsky PE, Smolen JS. Criteria for early rheumatoid arthritis: from Bayes' law revisited to new thoughts on pathogenesis. Arthritis Rheum 2002;46:1155-9.

8 Van der Heijde DM, van't Hof MA, van Riel PL, Theunisse LA, Lubberts EW, van Leeuwen MA, et al. Judging disease activity in clinical practice in rheumatoid arthritis: first step in the development of a disease activity score. Ann Rheum Dis 1990;49:916-20.

9 Van der Horst-Bruinsma I, Speyer I, Visser H, Breedveld FC, Hazes JM. Diagnosis and course of early-onset arthritis: results of a special early arthritis clinic compared to routine patient care. Br J Rheumatol 1998;37:1084-8.

10 Ropes MW, Bennett GA, Cobb S, Jacox R, Jessar RA. 1958 Revision of diagnostic criteria for rheumatoid arthritis. Bull Rheum Dis 1958;9:175-6.

11 Van der Heijde DM. How to read radiographs according to the Sharp/van der Heiide method. J Rheumatol 1999:26:743-5.

12 Fries JF, Spitz P, Kraines RG, Holman HR. Measurement of patient outcome in arthritis. Arthritis Rheum 1980;23:137-45.

13 Hulsmans HM, Jacobs JW, van der Heijde DM, Albada-Kuipers GA Schenk Y, Biilsma JW. The course of radiologic damage during the first six years of rheumatoid arthritis. Arthritis Rheum 2000:43:1927-40.

14 Wolfe F, Sharp JT. Radiographic outcome of recent-onset rheumatoid arthritis: a 19-year study of radiographic progression. Arthritis Rheum 1998:41:1571-82

15 Van Aken J, Lard LR, le Cessie S, Hazes JM, Breedveld FC, Huizinga TW. Radiological outcome after four years of early versus delayed treatment strategy in patients with recent onset rheumatoid arthritis. Ann Rheum Dis 2004;63:274-9.

16 Kaarela K, Tiitinen S, Luukkainen R. Long-term prognosis of monoarthritis. A follow-up study. Scand J Rheumatol 1983;12:374-6.

17 Machold KP, Stamm TA, Eberl GJ, Nell VK, Dunky A, Uffmann M, et al. Very recent onset arthritis - clinical, laboratory, and radiological findings during the first year of disease. J Rheumatol 2002;29:2278-87.

18 Pruijn G, Vossenaar E, Drijfhout J, van Venrooij W, Zendman A. Anti-CCP antibody detection facilitates early diagnosis and prognosis of rheumatoid arthritis. Curr Rheumatol Rev 2005;1:1-7. 